\title{
Taste Masking Technology: Recent Developments and Approaches
}

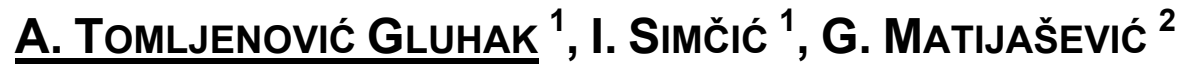 \\ ${ }^{1}$ PLIVA Croatia Ltd., Zagreb, Croatia \\ ${ }^{2}$ Faculty of Chemical Engineering and Technology, University of Zagreb, Croatia \\ E-mail: anamarija.tomljenovic-gluhak@pliva.com (A. Tomljenović Gluhak)
}

Sci Pharm. 2010; 78: 658

doi:10.3797/scipharm.cespt.8.PMS31

Taste-masking technologies are important for obtaining high-patient compliance and drug therapy efficiency, since many oral-delivery drugs have unpleasant qualities such as bitterness, sourness or saltiness.

Taste-masking technology includes two aspects: selection of appropriate tastemasking substances (polymers, flavourings, sweeteners, amino acids, etc.) and selection of appropriate taste-masking technique. Such taste-masked multiparticulate systems (granules, powders, dry syrups, or suspensions) represent further base for preparation of peroral formulations, such as dispersible tablets and oral liquids.

Selection of appropriate taste masking technique can strongly impact both, quality of taste masking and the process efficiency. There are many available techniques for taste masking developed today, including conventional granulation and polymer coating, but also more sophisticated is taste masking by encapsulation with lipids or cyclodextrins or by making multiple emulsions [1].

The aim of this study was to reduce or completely inhibit bitterness of model drug of defined physical-chemical characteristics. Fluid bed technology was used as the suitable method for taste masking. Drug particles were coated with the polymeric material, which ensured masking the bitter taste of the drug substance. Two different polymers, amino methacrylate copolymer (Eudragit ${ }^{\circledR} \mathrm{E}$ $\mathrm{PO}$ ) and ethylcellulose (Aquacoat ECD) were used. Influence of spray position and process parametrs on quality of coating of drug particles was studied. Physico-chemical properties of formed granules were characterised and compared in terms to ensure proper masking of drug bitterness and process efficiency [2].

This work was supported by scientifically assistance and knowledge share of Gordana Matijašević and Ivan Simčić in performing analytical tests.

[1] Lieberman HA, Lachman L, Schwartz BJ. Pharmaceutical dosage forms, Chewable tablets. Second edition (1989); Volume 1, 8: 367-415.

[2] Rambali B, Baert L, Massart DL. Scaling up of the fluidized bed granulation process. Int J Pharm. 2003; 252: 197-206. doi:10.1016/S0378-5173(02)00646-4 